\title{
Development and characterization of microsatellite loci in Excentrodendron hsienmu (Chun \& How) H.T. Chang \& R.H. Miau
}

\author{
W.H. Shen ${ }^{1,2,3}$, Z.H. Li ${ }^{1}$, Y.H. Peng ${ }^{2,3}$, M.H. Yang ${ }^{1}$, Z.Q. Tan ${ }^{2,3}$ and W. Zheng ${ }^{2,3}$ \\ ${ }^{1}$ Central South University of Forestry and Technology, Changsha, Hunan, China \\ ${ }^{2}$ Guangxi Key Laboratory of Superior Timber Trees Resource Cultivation, \\ Guangxi Forestry Research Institute, Nanning, Guangxi, China \\ ${ }^{3}$ Guangxi Forestry Research Institute, Nanning, Guangxi, China \\ Corresponding author: Z.H. Li \\ E-mail:1zh1957@126.com
}

Genet. Mol. Res. 15 (3): gmr. 15038060

Received August 8, 2015

Accepted November 26, 2015

Published August 18, 2016

DOI http://dx.doi.org/10.4238/gmr.15038060

Copyright $(2016$ The Authors. This is an open-access article distributed under the terms of the Creative Commons Attribution ShareAlike (CC BY-SA) 4.0 License

\begin{abstract}
Microsatellite markers were isolated using dualsuppression-PCR for the endangered species Excentrodendron hsienmu (Tiliaceae) to evaluate the genetic diversity and population structure of this species. A total of 11 polymorphic microsatellite loci were characterized in E. hsienmu. The number of alleles per locus ranged from 2 to 9, with an average of 5.27. The expected heterozygosity value ranged from 0.053 to 0.780 , with an average of 0.568 and the observed heterozygosity value ranged from 0 to 0.595 , with an average of 0.268 . The polymorphic information content value ranged from 0.051 to 0.740 , with an average of 0.521 . These newly
\end{abstract}


designed markers will be of great potential significance and profound influence in future research related to the genetic diversity, population structure, and patterns of gene flow of this species, which will contribute to the implementation of conservation and management strategies for this species.

Key words: Genetic diversity; Microsatellite loci; SSRs;

Excentrodendron hsienmu (Chun \& How) Hung T. Chang \& R.H. Miao

\section{INTRODUCTION}

Excentrodendron hsienmu (Chun \& How) Hung T. Chang \& R.H. Miao, commonly known as hsienmu or huomushu, is an evergreen tree distributed in the limestone rainforest exclusively restricted to Guangxi, Yunnan, in southeastern China, and Vietnam (Tang et al., 2007). It is one of the most economically important hardwoods prized for making chopping blocks, furniture, and fuel wood due to its extraordinary hardness and long-burning time (Tang et al., 2005). Because of anthropogenic activities, the individuals and populations of E. hsienmu have been in severe decline in the past years and are listed on International Union for Conservation of Nature (IUCN) Red Lists of threatened species (IUCN, 2015). While a better understanding of the genetic diversity and population structure in this species could implement effective conservation and management strategies to protect this important germplasm resource, only one such study on genetic diversity of this species has been reported that utilized inter-simple sequence repeat (ISSR) markers (Gao, 2006). However, ISSR loci are dominant markers and are difficult to use in the calculation of heterozygosity and paternity analysis, suggesting that additional polymorphic genetic markers are needed. Microsatellites or simple-sequence repeat (SSR) loci are co-dominant, highly polymorphic, multi-allelic, reproducible, locus-specific, and are abundantly dispersed throughout the plant genome (Gupta and Varshney, 2000). Here, we report the development of 11 polymorphic microsatellite markers for E. hsienmu that will be used in the study of genetic diversity and population structure in the future.

\section{MATERIAL AND METHODS}

Total genomic DNA was isolated from silica dried leaves from a single E. hsienmu individual from the Longzhou, Guangxi population $\left(106^{\circ} 56^{\prime} 37^{\prime \prime N} ; 22^{\circ} 27^{\prime} 53^{\prime \prime E}\right)$ using aDNeasy Plant Mini Kit (QIAGEN, Hilden, Germany) according to the manufacturer instructions. The concentration of genomic DNA was determined by running the samples on a $1.5 \%$ agarose gel. Microsatellites were developed following the dual-suppression-PCR protocol (Lian et al, 2006). Total genomic DNA was digested with the EcoRV or HaeIII restriction enzymes (Takara, Dalian, China) in order to construct a DNA library for E. hsienmu. The digested fragments were ligated with a specific blunt adaptor (consisting of a 48-mer upper strand: 5'-GTAATACGACTCACTATAGGGCACGCGTGGTCGACGGCCCGGGCTGGT-3', and an 8-mer lower strand with the 3'-end capped by the amino residue: 5'-ACCAGCCC$\mathrm{NH}_{2}-3^{\prime}$ ) by T4 DNA ligase (Takara). The fragments were then PCR-amplified from the

Genetics and Molecular Research 15 (3): gmr.15038060 
EcoRV or HaeIII DNA library using the compound SSR primer $(\mathrm{AC})_{6}(\mathrm{AG})_{5}$ or $(\mathrm{TC})_{6}(\mathrm{AC})_{5}$ and an $\mathrm{AP}_{2}$ adaptor (5'-CTATAGGGCACGCGTGGT-3'). Each 50- $\mu \mathrm{L}$ PCR volume contained 25-50 ng genomic DNA, 1X PCR buffer with $\mathrm{MgCl}_{2}, 0.2 \mathrm{mM}$ dNTPs, $0.5 \mathrm{U}$ ExTaq polymerase (Takara), and $0.5 \mathrm{mM}$ each compound SSR and $\mathrm{AP}_{2}$ primers. The PCR amplification conditions were as follows: 1 cycle of $10 \mathrm{~min}$ at $94^{\circ} \mathrm{C}, 30 \mathrm{~s}$ at $62^{\circ} \mathrm{C}$, and 1 min at $72^{\circ} \mathrm{C} ; 5$ cycles each of $30 \mathrm{~s}$ at $94^{\circ} \mathrm{C}, 30 \mathrm{~s}$ at $62^{\circ} \mathrm{C}$, and $1 \mathrm{~min}$ at $72^{\circ} \mathrm{C} ; 35$ cycles each of $30 \mathrm{~s}$ at $94^{\circ} \mathrm{C}, 30 \mathrm{~s}$ at $60^{\circ} \mathrm{C}$, and $1 \mathrm{~min}$ at $72^{\circ} \mathrm{C}$; and a final cycle of $30 \mathrm{~s}$ at $94^{\circ} \mathrm{C}, 30$ $\mathrm{s}$ at $60^{\circ} \mathrm{C}$, and $9 \mathrm{~min}$ at $72^{\circ} \mathrm{C}$. The PCR products were purified using a DNA clean-up kit (Axygen, Union, CA, USA), and ligated into pMD 19-T vector (Takara), and transformed into DH5 $\alpha$ competent cells (Takara). A single clone was confirmed using the M13 universal primers (M13 forward primer: 5'-TGTAAAACGACGGCCAGT-3'; M13 reverse primer: 5'-CAGGAAACAGCTATGACC-3'). Positive clones were sent to Life Technologies for sequencing on an ABI Prism 3730 automated DNA sequencer (Applied Biosystems, Foster City, CA, USA). Specific primers were designed based on sequences flanking the compound SSR using Primer Premier ver. 5.0 (Clarke and Gorley, 2001).

The primer pairs of the designed gene and compound SSR primer were used to amplify microsatellite repeats from 37 individuals from two $E$. hsienmu populations: the Longzhou (LZ), Guangxi population and the Hekou (HK), Yunnan population (103 ${ }^{\circ} 55^{\prime} 45^{\prime \prime} \mathrm{N}$; $\left.22^{\circ} 40^{\prime} 40^{\prime \prime} \mathrm{E}\right)$. Voucher specimens for the sampled populations have been deposited in the Guangxi Key Laboratory of Superior Timber Trees Resource Cultivation, Guangxi Forestry Research Institute. In order to examine their effectiveness and levels of polymorphism, the 5 '-end of the compound SSR primers were labeled with fluorescent dyes (FAM or HEX). The amplified products were analyzed using fluorescence capillary electrophoresis on an ABI Prism 3730 automated DNA sequencer (Applied Biosystems). The data were compiled and scored using GeneMaker 2.2.0 (Soft-Genetics, State College, PA, USA). Cervus 3.0 (Kalinowski et al., 2007) was used to calculate $N_{\mathrm{A}}$ (number of alleles per locus), $H_{\mathrm{O}}$ (observed heterozygosity), $H_{\mathrm{E}}$ (expected heterozygosity), and PIC (polymorphic information content). Genepop (http:// genepop.curtin.edu.au/) was employed to test the Hardy-Weinberg equilibrium (HWE) and linkage disequilibria (LD).

\section{RESULTS}

In total, 11 microsatellite loci were identified (Table 1) from the tested plant material All 11 loci were successfully amplified in the 32 individuals collected from the two $E$. hsienmu populations. The $N_{\mathrm{A}}$ ranged from 2 to 9 alleles, with an average of 5.27. Individually, the LZ population $N_{\mathrm{A}}$ ranged from 2 to 7 , with an average of 4.4; in the HK population the $N_{\mathrm{A}}$ ranged from 1 to 8 , with an average of 4.1. The $H_{\mathrm{O}}$ and $H_{\mathrm{E}}$ values ranged from 0 to 0.595 , with an average of 0.268 ( 0 to 0.682 , with an average of 0.298 in the LZ population; 0 to 0.533 , with an average of 0.224 in the HK population), and ranged from 0.053 to 0.780 , with an average of 0.568 ( 0.045 to 0.741 , with an average of 0.539 in the LZ population; 0 to 0.893 , with an average of 0.580 in the HK population), respectively. The PIC values were from 0.051 to 0.740 , with an average of 0.521 ( 0.043 to 0.679 , with an average of 0.486 in the LZ population; 0 to 0.786 , with an average of 0.517 in the HK population) (Tables 1 and 2). Most of the microsatellite loci deviated significantly from the HWE $(\mathrm{P}<0.001)$. The pairwise LD between the 11 pairs of loci was not significant $(\mathrm{P}>0.001)$.

Genetics and Molecular Research 15 (3): gmr.15038060 
Table 1. Characterization of 11 polymorphic microsatellite loci developed for Excentrodendron hsienmu.

\begin{tabular}{|c|c|c|c|c|c|c|c|c|c|}
\hline Locus & Primers sequences $\left(5^{\prime}-3^{\prime}\right)$ & Repeat motif & $\mathrm{Ta}\left({ }^{\circ} \mathrm{C}\right)$ & Allele size (bp) & $N_{\mathrm{A}}$ & $H_{\mathrm{O}}$ & $H_{\mathrm{E}}$ & PIC & Accession No. \\
\hline XmSSR1 & $\begin{array}{l}\text { F: ACACACACACACAGAGAGAGAG } \\
\text { R: ACCCTGCAAATAATAAATAACC }\end{array}$ & $(\mathrm{AC})_{6}(\mathrm{AG})_{8} \ldots(\mathrm{AGGG})_{3}$ & 56 & 92 & 4 & 0.324 & 0.701 & 0.638 & KU064726 \\
\hline XmSSR2 & $\begin{array}{l}\text { F: ACACACACACACAGAGAGAGAG } \\
\text { R: TTCAGGGTTCAGCATTCAAAGT }\end{array}$ & $(\mathrm{AC})_{6}(\mathrm{AG})_{5}$ & 56 & 192 & 5 & 0.270 & 0.577 & 0.522 & KU064727 \\
\hline XmSSR3 & $\begin{array}{l}\text { F: ACACACACACACAGAGAGAGAG } \\
\text { R: TAACCACCAAAGTCCAACGAAAA }\end{array}$ & $(\mathrm{AC})_{6}(\mathrm{AG})_{7}$ & 56 & 139 & 4 & 0.324 & 0.679 & 0.613 & KU064728 \\
\hline XmSSR4 & $\begin{array}{l}\text { F: ACACACACACACAGAGAGAGAG } \\
\text { R: TTGGAGGGATAGAAAGTTTACG }\end{array}$ & $(\mathrm{AC})_{6}(\mathrm{AG})_{5}$ & 56 & 100 & 8 & 0.216 & 0.625 & 0.595 & KU064729 \\
\hline XmSSR5 & $\begin{array}{l}\text { F: ACACACACACACAGAGAGAGAG } \\
\text { R: CATAGTCACCGACATCATAATCC }\end{array}$ & $(\mathrm{AC})_{6}(\mathrm{AG})_{5}$ & 56 & 122 & 2 & 0.000 & 0.053 & 0.051 & KU064730 \\
\hline XmSSR6 & $\begin{array}{l}\text { F: ACACACACACACAGAGAGAGAG } \\
\text { R: ACATTCTGAGATGCCATAGTTT }\end{array}$ & $(\mathrm{AC})_{6}(\mathrm{AG})_{5}$ & 56 & 149 & 5 & 0.243 & 0.662 & 0.585 & KU064731 \\
\hline XmSSR7 & $\begin{array}{l}\text { F: ACACACACACACAGAGAGAGAG } \\
\text { R: GGTTCAATTTGATCGACGAGAC }\end{array}$ & $(\mathrm{AC})_{6}(\mathrm{AG})_{8}$ & 56 & 162 & 5 & 0.432 & 0.671 & 0.598 & KU064732 \\
\hline XmSSR8 & $\begin{array}{l}\text { F: ACACACACACACAGAGAGAGAG } \\
\text { R: GTGGTTTGCTCACATCGGACTC }\end{array}$ & $(\mathrm{AC})_{6}(\mathrm{AG})_{6}$ & 56 & 134 & 7 & 0.351 & 0.745 & 0.691 & KU064733 \\
\hline XmSSR9 & $\begin{array}{l}\text { F: ACACACACACACAGAGAGAGAG } \\
\text { R: AGTGAAAGAAACGAGCAATGAA }\end{array}$ & $(\mathrm{AC})_{6}(\mathrm{AG})_{6}$ & 56 & 140 & 9 & 0.135 & 0.780 & 0.740 & KU064734 \\
\hline XmSSR10 & $\begin{array}{l}\text { F: TCTCTCTCTCTCACACACACAC } \\
\text { R: ACATCACCAACCTTCGCATCAG }\end{array}$ & $(\mathrm{TC})_{6}(\mathrm{AC})_{5}$ & 56 & 116 & 3 & 0.054 & 0.054 & 0.052 & KU064735 \\
\hline XmSSR11 & $\begin{array}{l}\text { F: TCTCTCTCTCTCACACACACAC } \\
\text { R: ATTCGTTGGATTCCATGATTAA }\end{array}$ & $(\mathrm{TC})_{6}(\mathrm{AC})_{5}$ & 56 & 94 & 6 & 0.595 & 0.699 & 0.647 & KU064736 \\
\hline
\end{tabular}

$\mathrm{Ta}=$ annealing temperature used in PCR; $N_{\mathrm{A}}=$ number of alleles; $H_{\mathrm{O}}=$ observed heterozygosity; $H_{\mathrm{E}}=$ expected heterozygosity; PIC = polymorphic information content.

Table 2. Genetic diversity of 11 microsatellite loci in two populations of Excentrodendron hsienmu.

\begin{tabular}{l|c|c|c|c|c|c|c|c}
\hline \multirow{2}{*}{ Locus } & \multicolumn{3}{|c|}{$\begin{array}{c}\text { Longzhou, Guangxi (N=22) } \\
106^{\circ} 56^{\prime} 37^{\prime \prime N} ; 22^{\circ} 27^{\prime} 53^{\prime \prime} \mathrm{E}\end{array}$} & \multicolumn{4}{c}{$\begin{array}{l}\text { Hekou, Yunnan (N=15) } \\
103^{\circ} 55^{\prime} 45^{\prime \prime} \mathrm{N} ; 22^{\circ} 40^{\prime} 40^{\prime \prime} \mathrm{E}\end{array}$} \\
\cline { 2 - 9 } & $N_{\mathrm{A}}$ & $H_{\mathrm{O}}$ & $H_{\mathrm{E}}$ & PIC & $N_{\mathrm{A}}$ & \multicolumn{1}{c}{$H_{\mathrm{O}}$} & $H_{\mathrm{E}}$ & PIC \\
\hline XmSSR1 & 4 & 0.364 & 0.701 & $0.628^{* * *}$ & 4 & 0.267 & 0.671 & $0.586^{* * *}$ \\
\hline XmSSR2 & 5 & 0.318 & 0.561 & $0.510^{* * *}$ & 4 & 0.200 & 0.609 & $0.528^{* * *}$ \\
\hline XmSSR3 & 4 & 0.455 & 0.728 & $0.658^{* * *}$ & 3 & 0.133 & 0.579 & $0.499^{* * *}$ \\
\hline XmSSR4 & 5 & 0.182 & 0.520 & $0.483^{* * *}$ & 6 & 0.267 & 0.726 & $0.664^{* * *}$ \\
\hline XmSSR5 & 2 & 0.000 & 0.089 & $0.083^{*}$ & 1 & 0.000 & 0.000 & 0.000 \\
\hline XmSSR6 & 5 & 0.318 & 0.707 & $0.629^{* * *}$ & 3 & 0.133 & 0.570 & $0.456^{* * *}$ \\
\hline XmSSR7 & 3 & 0.500 & 0.587 & 0.494 n.s. & 5 & 0.333 & 0.756 & $0.685^{* * *}$ \\
\hline XmSSR8 & 7 & 0.227 & 0.741 & $0.679^{* * *}$ & 4 & 0.533 & 0.756 & $0.683^{* * *}$ \\
\hline XmSSR9 & 5 & 0.182 & 0.682 & $0.631^{* * *}$ & 8 & 0.067 & 0.839 & $0.786^{* * *}$ \\
\hline XmSSR10 & 2 & 0.045 & 0.045 & 0.043 & 2 & 0.067 & 0.067 & 0.062 \\
\hline XmSSR11 & 6 & 0.682 & 0.569 & 0.504 n.s & 5 & 0.467 & 0.802 & $0.739^{* * *}$ \\
\hline Mean & 4.4 & 0.298 & 0.539 & 0.486 & 4.1 & 0.224 & 0.580 & 0.517 \\
\hline
\end{tabular}

$\mathrm{N}=$ sample size for each population. ***and***significant departures from Hardy-Weinberg equilibrium at $\mathrm{P}<$ $0.05, \mathrm{P}<0.01, \mathrm{P}<0.001$, respectively. $\mathrm{n} . \mathrm{s} .=$ not significant.

\section{DISCUSSION}

The 11 novel microsatellite loci developed in E. hsienmu in this study was evaluated in two populations. The mean $N_{\mathrm{A}}, H_{\mathrm{O}}, H_{\mathrm{E}}$ and PIC values were 5.27, 0.268, 0.568 and 0.521 , respectively, which show high levels of polymorphism, indicating that these newly designed markers will be of great potential significance and profound influence in future research related to the genetic diversity, population structure, and patterns of gene flow of this species, which will contribute to implement the conservation and management strategies of this species.

\section{Conflicts of interest}

The authors declare no conflict of interest.

Genetics and Molecular Research 15 (3): gmr.15038060 


\section{ACKNOWLEDGMENTS}

Research supported by the Open Research Fund of Guangxi Key Laboratory of Superior Timber Trees Resource Cultivation (grant \#13B0101).

\section{REFERENCES}

Clarke KR and Gorley RN (2001). Primer v5: User manual/tutorial. Primer-E Ltd., Plymouth.

Gao H (2006). A biological study of Excentrodendron hsienmu H.T.Chang \& R.H. Miau and its significance in conservation ecology. Doctoral thesis, Sichuan University, Chengdu.

Gupta PK and Varshney RK (2000). The development and use of microsatellite markers for genetic analysis and plant breeding with emphasis on bread wheat. Euphytica 113: 163-185. http://dx.doi.org/10.1023/A:1003910819967

IUCN (2015). The IUCN Red List of Threatened Species. Available at [http://www.iucnredlist.org/]. Accessed March 2015.

Kalinowski ST, Taper ML and Marshall TC (2007). Revising how the computer program CERVUS accommodates genotyping error increases success in paternity assignment. Mol. Ecol. 16: 1099-1106. PubMed http://dx.doi. org/10.1111/j.1365-294X.2007.03089.x

Lian CL, Abdul Wadud M, Geng Q, Shimatani K, et al. (2006). An improved technique for isolating codominant compound microsatellite markers. J. Plant Res. 119: 415-417. PubMed http://dx.doi.org/10.1007/s10265-006-0274-2

Tang Y, Mao LH and Gao H (2005). Over-exploitation and lack of protection is leading to a decline of a protected calcicolous tree species Excentrodendron hsienmu (Tiliaceae) in China. Biol. Conserv. 126: 14-23. http://dx.doi. org/10.1016/j.biocon.2005.04.016

Tang Y, Gilbert MG and Dorr LJ (2007). Tiliaceae A. L. Jussieu. In: Flora of China. Science Press, Beijing. 